\title{
Do women with benign versus malignant ovarian masses demonstrate variable clinical presentation?
}

\author{
Nilajkumar D. Bagde ${ }^{1}$, Madhuri Bagde ${ }^{2 *}$, Sarita Agrawal' ${ }^{1}$ Zamir A. Lone ${ }^{1}$, Nighat Hussain ${ }^{3}$
}

${ }^{1}$ Department of Obstetrics and Gynecology, ${ }^{3}$ Department of Pathology, AIIMS, Raipur, Chhattisgarh, India

${ }^{2}$ Department of Gynecology, New Life clinic, Nagpur, Maharashtra, India

Received: 07 December 2020

Revised: 13 December 2020

Accepted: 14 December 2020

\author{
*Correspondence: \\ Dr. Madhuri Bagde, \\ E-mail: newlifeclinicnag@gmail.com
}

Copyright: () the author(s), publisher and licensee Medip Academy. This is an open-access article distributed under the terms of the Creative Commons Attribution Non-Commercial License, which permits unrestricted non-commercial use, distribution, and reproduction in any medium, provided the original work is properly cited.

\begin{abstract}
Background: Early diagnosis of ovarian tumors is a challenge due to variable presentation. Early diagnosis of ovarian cancers aids in timely management and better clinical outcomes. Aim of study was to determine the different clinical presentations of ovarian tumors and compare those in benign tumors versus malignancies.

Methods: Clinical data of all women operated for ovarian masses was extracted from case files at a tertiary care centre and evaluated and clinical features compared in women with benign versus malignant tumors.

Results: We found 50 cases of ovarian tumors with $26 \%$ malignancies. The mean age was $38.48+14.9$ years. Malignancies were significantly common in menopausal than menstruating $(\chi 2=13.57, \mathrm{p}=0.001$, fishers exact $)$. Pain was the commonest symptom and combined lumbar and iliac pain was reported in $67 \%$ cases. The location of pain was not significantly different in women with malignancy compared to those with benign tumors (likelihood ratio $\chi 2=7.93, \mathrm{p}=0.24)$. The odds of reporting a mass in abdomen were significantly greater in women with cancers than benign tumors $(\mathrm{OR}=4.9,95 \% \mathrm{CI} 1.07-24.06, \mathrm{p}=0.01)$. More women with cancer had history of distension of abdomen compared to women with benign tumors $(\chi 2=9.43, \mathrm{p}=0.002)$.

Conclusions: Lumbar pain is most frequent complaint in women with ovarian pathology. Symptoms of distension in abdomen or presence of lump in abdomen are a significant guide to alert the physician regarding possibility of malignancy must be evaluated without delay.
\end{abstract}

Keywords: Ovarian tumors, Clinical features, Cancer, Oncology, Gynecology, Gynec-oncology

\section{INTRODUCTION}

Adnexal masses form prime gynaecological pathologies and of these about $2 / 3 \mathrm{rd}$ is ovarian tumors. ${ }^{1}$ Ovarian cancer ranks the 3rd or 4th cancer in India going by the data from different cancer registries across the country and only $4.8 \%$ cases were diagnosed clinically. ${ }^{2}$ Ovarian cancer shows a rise in incidence from 35 years of age and peaks between 55 and 64 years, with a higher incidence in menopausal women. ${ }^{3-5}$ Information regarding the clinical features of ovarian tumors and if the features differ in benign versus malignant cases is limited. Ovarian malignancies are usually diagnosed late only when they attain a bigger size. Small ovarian mass which are likely to be missed on physical examination pose a diagnostic challenge. ${ }^{6}$ A clinical guide to the presence of malignancy may increase the chance of a favourable outcome. This study was undertaken to try and evaluate if clinical features, especially history of the patient differs in women with benign tumors compared to malignant ones.

\section{METHODS}

This hospital based retrospective observational study was carried out at the Department of Obstetrics and 
Gynecology, All India Institute of Medical Sciences (AIIMS), Raipur, India. After seeking approval from the ethical committee, a search of case files of all women admitted with a diagnosis of ovarian tumors in the Obstetrics and Gynecology department between from December 2016 to December 2019 was made. All women that underwent a surgery for ovarian tumor and had an available histopathological report were included in the study irrespective of age. Women in whom histopathological reports were not available and women in whom surgery and histopathology failed to reveal an ovarian tumor were excluded from the study. Results were analyzed using stata 64. Comparisons were made between age profile, presence of pain, its duration, location, presence of lump in abdomen, distension of abdomen, any other complaints, menstrual irregularities, menopausal status, abdominal examination findings of palpable mass and tenderness. The age was subcategorised as less than 20 years, 20 to 45 years and more than 45 years to facilitate analysis. Pain was categorised according to its location and comparisons were made for pain as an isolated finding in a region and also for presence of pain in more than one region. Pain was sub categorised into acute pain when it was present for less than 6 months and chronic for more than six months. Menstrual irregularities were examined for all women and a further subgroup analysis was done after excluding those that attained menopause. These variables were compared in women with benign versus malignant tumors. The tests used were chi square, fishers exact, likelihood ratio chi square test and one-way ANOVA. ODDs ratio was determined for women with benign versus malignant tumors and significance tested.

\section{RESULTS}

Data was available for 50 women. Malignancy was reported on histopathology in $26 \%$ women while $74 \%$ had benign tumors. The mean age was $38.48+14.9$ years (Table 1). The youngest patient was 12 years and oldest 74 years of age. Of these, $10 \%$ were below 20 years of age, $64 \%$ between 20 to 45 years and $26 \%$ were more than 45 years of age. The mean parity was 1.9 , ranging from zero to five. $76 \%$ women were menstruating while $24 \%$ were menopausal. More menopausal women had malignancies compared to those that were menstruating $(\chi 2=13.57, \mathrm{p}=0.001$, fishers exact). Of the menstruating women ( $n=38), 23.68 \%$ gave history of irregular periods. However, there was no relationship between regularity of periods and presence of cancer in these women $(\chi 2=0.04$, $\mathrm{p}=1$, fishers exact).

Pain was reported as a symptom in $80 \%$ (Table 2.3). Of those women having pain, $35 \%$ had pain for less than 1 month. In $35 \%$ women, pain was present for 1 month to 6 months and in $10 \%$ cases each the history of pain was for six months to one year, one to two year and more than five years in duration. Amongst those that had pain $(n=40), 65 \%$ had history of acute pain for less than six months and $35 \%$ had chronic pain for six months to more than two years. History of acute pain (less than 6 months) versus chronic pain (more than 6 months) was not statistically different in women with malignancy compared to those with benign tumors $(\mathrm{N}=40, \chi 2=2.91$, $\mathrm{p}=0.12$ fishers exact).

Table 1: Age, parity, menstrual history and menopausal status.

\begin{tabular}{|c|c|c|c|c|c|}
\hline Variables & $\begin{array}{l}\text { Overall: } \\
\mathrm{n}=\mathbf{5 0}\end{array}$ & $\begin{array}{l}\text { Benign } \\
\text { overall: } n=\mathbf{5 0}\end{array}$ & $\begin{array}{l}\text { Malignant } \\
\text { overall: } n=\mathbf{5 0}\end{array}$ & $\begin{array}{l}\text { Distribution in all } \\
\text { benign cases } n=37\end{array}$ & $\begin{array}{l}\text { Distribution in all } \\
\text { malignant cases } \\
n=13\end{array}$ \\
\hline & $\mathbf{N}(\%)$ & $\mathbf{N}(\%)$ & $\mathbf{N}(\%)$ & $\%$ & $\%$ \\
\hline \multicolumn{6}{|l|}{ Age (in years) } \\
\hline$<20$ & $5(10)$ & $5(10)$ & $0(0)$ & 13.51 & 0 \\
\hline $20-45$ & $32(64)$ & $28(56)$ & $4(8)$ & 75.68 & 30.77 \\
\hline$>45$ & $13(26)$ & $4(8)$ & $9(18)$ & 10.81 & 69.23 \\
\hline \multicolumn{6}{|l|}{ Parity } \\
\hline Unmarried & $10(20)$ & $10(20)$ & 0 & 27.03 & 0 \\
\hline Para 0 & $5(10)$ & $3(6)$ & $2(4)$ & 8.11 & 15.38 \\
\hline Para 1 & $7(14)$ & $6(12)$ & $1(2)$ & 16.22 & 7.69 \\
\hline Para 2 & $11(22)$ & $9(18)$ & $2(4)$ & 24.32 & 15.38 \\
\hline Para 3 & $7(14)$ & $4(8)$ & $3(6)$ & 10.81 & 23.08 \\
\hline Para 4 & $5(10)$ & $2(4)$ & $3(6)$ & 5.41 & 23.08 \\
\hline Para 5 & $5(10)$ & $3(6)$ & $2(4)$ & 8.11 & 15.38 \\
\hline $\begin{array}{l}\text { Menstrual } \\
\text { irregularity }\end{array}$ & $10(20)$ & $9(18)$ & $1(2)$ & 24.32 & 7.69 \\
\hline $\begin{array}{l}\text { Attained } \\
\text { menopause }\end{array}$ & $12(24)$ & $4(8)$ & $8(16)$ & 10.81 & 61.54 \\
\hline
\end{tabular}

Of those that had pain, combined lumbar and iliac pain was reported in $67 \%$ cases and was the commonest site. Other locations of pain were iliac pain in $12 \%$, lumbar pain in $10 \%$, diffuse pain in $5 \%$ and pain in hypogastric and epigastric region in $2.5 \%$ each. No patient with cancer had isolated lumbar pain versus $10.81 \%$ with 
benign tumors. Isolated iliac pain was reported in $7.69 \%$ women with malignancies compared to $10.81 \%$ with benign tumors. Combined lumbar and iliac pain was reported $53.84 \%$ women with malignancies compared to $54.05 \%$ women with benign masses. $7.69 \%$ women with malignancies had pain in hypogastric region while none with benign tumors had pain in that location. No women with malignancy reported epigastric pain or diffuse pain versus $7.69 \%$ and $15.38 \%$ in those with benign tumors respectively. The location of pain was also not significantly different in women with malignancy compared to those with benign tumors (likelihood ratio $\chi 2=7.93, p=0.24)$.

Table 2: Major clinical features in benign versus malignant tumors.

\begin{tabular}{|c|c|c|c|c|c|}
\hline Variables & $\begin{array}{l}\text { All } \\
\text { cases } \\
(\mathbf{n}=50)\end{array}$ & $\begin{array}{l}\text { Benign } \\
(n=50)\end{array}$ & $\begin{array}{l}\text { Malignant } \\
(\mathbf{n}=\mathbf{5 0})\end{array}$ & $\begin{array}{l}\text { Distribution } \\
\text { in benign } \\
\text { cases }(n=37)\end{array}$ & $\begin{array}{l}\text { Distribution } \\
\text { in malignant } \\
\text { cases }(n=13)\end{array}$ \\
\hline & $\%$ & $\%$ & $\%$ & $\%$ & $\%$ \\
\hline Isolated lumbar pain & 6 & 6 & 0 & 8.11 & 0 \\
\hline $\begin{array}{l}\text { Lumbar pain (isolated or with pain in another } \\
\text { region) }\end{array}$ & 62 & 48 & 14 & 64.86 & 53.85 \\
\hline Isolated iliac pain & 10 & 8 & 2 & 10.81 & 7.69 \\
\hline Iliac pain (isolated or with pain in another region) & 70 & 52 & 18 & 70 & 69.23 \\
\hline Lumbar and iliac pain & 54 & 40 & 14 & 54 & 53.85 \\
\hline $\begin{array}{l}\text { Hypogastric pain (isolated or with pain in any } \\
\text { other region) }\end{array}$ & 6 & 4 & 2 & 5.41 & 7.69 \\
\hline Epigastric and umbilical pain & 2 & 2 & 0 & 2.70 & 0 \\
\hline Acute pain (less than 6 months) & 54 & 36 & 18 & 48.65 & 69.23 \\
\hline Chronic pain (more than 6 months) & 46 & 38 & 8 & 51.35 & 30.77 \\
\hline Lump in abdomen & 34 & 18 & 16 & 61.54 & 24.32 \\
\hline Distension of abdomen & 28 & 14 & 14 & 18.92 & 53.85 \\
\hline Tumor incidental finding & 20 & 18 & 2 & 24.32 & 7.69 \\
\hline
\end{tabular}

Table 3: Significance of clinical features in benign versus malignant tumors.

\begin{tabular}{|llll|}
\hline Symptom $(\mathbf{n = 5 0})$ & Odds ratio & $\mathbf{9 5 \%}$ Confidence interval & P value for odds ratio \\
\hline Lumbar pain & 0.63 & $0.14-2.82$ & 0.48 \\
\hline Iliac pain & 1.45 & $0.02-30.18$ & 0.76 \\
\hline Hypogastric pain & 0.95 & $0.20-5.15$ & 0.94 \\
\hline Combined lumbar and iliac pain & 0.99 & $0.23-4.33$ & 0.98 \\
\hline Acute pain<6 months & 1.68 & $0.39-7.80$ & 0.42 \\
\hline Chronic pain>6 months & 0.59 & $0.12-2.54$ & 0.42 \\
\hline Lump in abdomen & 4.9 & $1.07-24.06$ & $0.01 *$ \\
\hline Distension of abdomen & 5.00 & $1.03-24.17$ & $0.01 *$ \\
\hline Tumor an Incidental finding & 0.25 & $0.005-2.31$ & 0.19 \\
\hline
\end{tabular}

*=value is significant

Table 4: Size of tumor on abdominal examination and presence of tenderness on palpation in benign versus malignant tumors.

\begin{tabular}{|c|c|c|c|c|c|}
\hline Variables & $\begin{array}{l}\text { Overall } \\
(n=50)\end{array}$ & $\begin{array}{l}\text { Benign overall } \\
(n=50)\end{array}$ & $\begin{array}{l}\text { Malignant } \\
\text { overall }(n=50)\end{array}$ & $\begin{array}{l}\text { Distribution in all } \\
\text { benign cases }(n=37)\end{array}$ & $\begin{array}{l}\text { Distribution in all } \\
\text { malignant cases }(n=13)\end{array}$ \\
\hline Size of mass & $\mathbf{N}(\%)$ & $\mathbf{N}(\%)$ & $\mathbf{N}(\%)$ & $\%$ & $\%$ \\
\hline Not palpable & $20(40)$ & $17(34)$ & $3(6)$ & 45.95 & 53.85 \\
\hline 12 weeks & 0 & 0 & 0 & 0 & 0 \\
\hline 13-16 weeks & $8(16)$ & $6(12)$ & $2(4)$ & 16.22 & 15.38 \\
\hline $17-20$ weeks & $8(16)$ & $7(14)$ & $1(2)$ & 18.92 & 7.69 \\
\hline 21-24 weeks & $6(12)$ & $3(6)$ & $3(6)$ & 8.11 & 23.08 \\
\hline 25-28 weeks & $2(4)$ & $1(2)$ & $1(2)$ & 2.70 & 7.69 \\
\hline$>28$ weeks & $5(10)$ & $3(6)$ & $2(4)$ & 8.11 & 15.38 \\
\hline Data not available & $1(2)$ & 0 & $1(2)$ & 0 & 7.69 \\
\hline $\begin{array}{l}\text { Tenderness on } \\
\text { palpation }\end{array}$ & $10(20)$ & 7 (14) & $3(6)$ & 18.92 & 23.08 \\
\hline
\end{tabular}




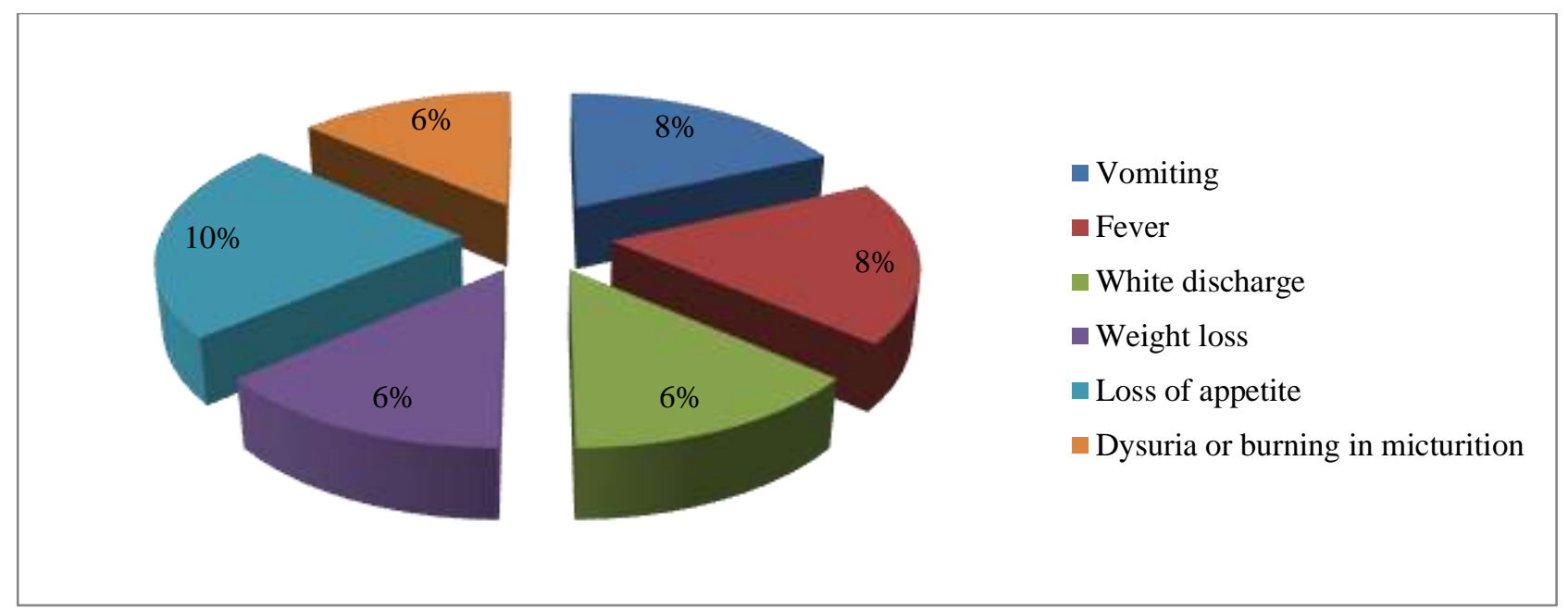

Figure 1: Additional symptoms in ovarian tumors: one woman may have more than one symptom.

A history of feeling of mass in abdomen was given by $34 \%$ and $28 \%$ gave history of distension of abdomen (Table 2, 3). Of those with malignancy, 53\% had distension. $29.41 \%$ of those that had a history of a mass in abdomen also gave history of distension, and $35.71 \%$ of those with history of distension had a history of mass in abdomen. Significantly more women with cancer had history of distension of abdomen compared to women with benign tumors $(\chi 2=9.43, \mathrm{p}=0.002)$.

In addition to the above, $10 \%$ women had history of loss of appetite, $6 \%$ had weight loss, $8 \%$ had vomiting, $8 \%$ had fever, $6 \%$ had white discharge, and burning in micturition was reported by $6 \%$ women (Figure 1). In $20 \%$ women, no history related to mass was present and it was an incidental finding on examination or ultrasonography.

On examination, the mass was either up to 12 weeks or 13-16 weeks pregnant uterus size in $16 \%$ patients each, in $12 \%$ it was $17-20$ weeks, $4 \%$ it was $21-24$ weeks, $10 \%$ it was $25-28$ weeks, and in $42 \%$ it was not palpable (Table 4). No significant difference was found with respect to size of mass on abdominal examination in women with cancer versus benign disease when tested by a one-way ANOVA $(p=0.81)$.

Tenderness was present in $20 \%$ women, $80 \%$ did not have any tenderness on palpation. No significant difference was found in tenderness on palpation in women with cancer compared to those with benign disease $(\chi 2=0.1, p=0.70$, fishers exact $)$.

\section{DISCUSSION}

The foremost part of a doctor patient communication aiding diagnosis is history. Ovarian tumors, though very common, present with a few symptoms that are striking and provide a lead to diagnosis. However, narrowing down the possibility of cancer from history and examination may provide early insights towards future evaluation and better therapeutic outcomes.

In our study $74 \%$ tumors were benign. The chances of malignancy increased with age and menopausal status, both showing a positive relation to presence of cancer, similar to reports by Okugawa et al. ${ }^{7}$ Malignant tumors were more common in postmenopausal women $(81 \%$ versus $29 \%, \mathrm{p}<0.001)$ in a study by Simsek et al. ${ }^{8}$ Early menopause has been proposed as a risk factor for ovarian cancer. ${ }^{9}$ Menopausal status had a higher correlation with early stage ovarian cancer as reported by Chirdchim et al. ${ }^{10}$ In this study, $84 \%$ women with benign tumors were less than 60 years of age. The mean age of women with cancer was 53.46 years compared to 33.21 years in benign tumors. Ghartimagar et al reported a similar result for surface epithelial ovarian tumors. ${ }^{11}$

Kanthikar reported that $55 \%$ non-neoplastic lesions were incidental findings in their study. ${ }^{12}$ In our study, $20 \%$ tumors were incidental with women having complaints other than those related to ovarian tumors and the masses were diagnosed on imaging or examination. ${ }^{12}$ There was no significant difference between the mass being an incidental finding in benign versus malignant tumors $(\chi 2=1.66, \mathrm{p}=0.19)$.

The commonest symptom was pain. It was seen in $69.23 \%$ women with malignancies and $83.78 \%$ women with benign lesions compared to $79.55 \%$ and $77.05 \%$ in a study by Baru et al. ${ }^{13}$ Radhamani et al also reported pain in $83 \%$ women with adnexal masses. ${ }^{14}$ Kuladeepa et al report abdominal pain as a symptom in $63.4 \%$ women with benign tumors and $68.2 \%$ with malignancies. ${ }^{15}$ In a large study by Goff et al, $22 \%$ of women with malignancies had pain. ${ }^{16}$ Most women in our study, presented to the clinic with pain within 6 months of its onset. Overall, $26 \%$ presented within the first month with pain. Baru et al report $52.27 \%$ with benign and $26.31 \%$ with malignancies presented within a month with pain. 13 In this study, even though women with malignancies had 
a higher chance of having pain for less than 6 months (odds ratio=2.35) and pain in iliac region (Odds Ratio=1.45) but the values were not significant. Overall, in this study, the location and duration of pain did not vary with type of tumor (Table 2,3 ).

Mass in abdomen is another complaint that is commonly encountered in ovarian tumors. Presence of lump in abdomen as a complaint has been reported from $43 \%$ to $78 \%$ in various studies. ${ }^{12,13,15,16} \mathrm{We}$ found that the odds of reporting a mass in abdomen were significantly greater in women with cancers compared to those with benign tumors $(\mathrm{OR}=4.9,95 \%$ CI 1.07-24.06, $\mathrm{p}=0.01)$. Ebell et al in a systematic review reported the likelihood ratio of 30 for presence of an abdominal mass and 16 for distension of abdomen. ${ }^{17}$

Distension of abdomen was the third commonest complaint in ovarian tumors. In this study $28 \%$ women had distension. Baru et al report distension in $43.18 \%$ benign and $70.49 \%$ women with malignant tumors. ${ }^{13} \mathrm{We}$ found that women with cancers had a higher probability of having distension in abdomen as compared to those with benign lesions $(\mathrm{OR}=5,95 \%$ CI 1.03-24.17, $\mathrm{p}=0.01)$ comparable to Goff et al (odds ratio $=7.4,95 \%$ confidence interval [CI], 3.8-14.2) (Table 3). ${ }^{16}$

The size of the tumor did not correlate with presence of cancer in this study (likelihood ratio $\chi 2=7.55, p=0.255$ ) (Table 4). We did not find literature with reference to tumor size on clinical examination for comparison of the same.

\section{Limitations}

The retrospective nature of the study limits the scope of interpretation of results.

\section{CONCLUSION}

Ovarian tumors continue to pose a clinical diagnostic challenge. The presence of a lump in abdomen or a history of distension in abdomen are significant complaints that must warn the clinician against the possibility of a malignant tumor and further evaluation undertaken for best clinical outcomes.

\section{Funding: No funding sources}

Conflict of interest: None declared

Ethical approval: The study was approved by the Institutional Ethics Committee

\section{REFERENCES}

1. Hassan AY, Ellatif a AAA, Darweesh FF. Twodimensional ultrasound and doppler in assessment of adnexal masses in correlation to histopathological analysis. Acad J Cancer Res. 2014;7(1):8-18.

2. Takiar R. Status of Ovarian Cancer in India. EC Gynaecol. 2019:358-64
3. Murthy NS, Shalini S, Suman G, Pruthvish S, Mathew A. Changing trends in incidence of ovarian cancer - the Indian scenario. Asian Pac J Cancer Prev. 2009;10(6):1025-30.

4. Sharadha SO, Sridevi TA, Renukadevi TK, Gowri R, Binayak D, Indra V. Ovarian masses: changing clinicohistopathological trends. J Obstet Gynaecol Ind. 2015;65(1):34-8.

5. Topuz S, Saygili H, Akhan S, Yavuz E, Turfanda A, Berkman S. Differentiation of benign and malignant adnexal masses: value of a morphologic scoring system. Eur J GynaecolOncol. 2005;26(2):209-12.

6. Margaret PF, Kirubamani VNH. Clinical correlation of ovarian mass with ultrasound findings and histopathology report. Int J Reproduct Contracept Obstet Gynecol. 2020;2017:5230-4.

7. Okugawa K, Hirakawa T, Fukushima K, Kamura T, Amada S, Nakano H. Relationship between age, histological type, and size of ovarian tumors. Int $\mathbf{J}$ Gynecol Obstet. 2001;74:45-50.

8. Simsek HS, Tokmak A, Ozgu E, Doganay M, Danisman N, Erkaya $\mathrm{S}$ et al. Role of a risk of malignancy index in clinical approaches to adnexal masses. Asian Pac J Cancer Prev. 2014;15(18):77937.

9. Cramer DW. Epidemiologic aspects of early menopause and ovarian cancer. Ann N Y Acad Sci. 1990;592:363-75;390-4.

10. Chirdchim W, Wanichsetakul P, Phinyo P, Patumanond J, Suwannarurk K, Srisomboon J. Development and Validation of a Predictive Score for Preoperative Diagnosis of Early Stage Epithelial Ovarian Cancer. Asian Pac J Cancer Prev. 2019;20(4):1207-13.

11. Ghartimagar D, Ghosh A, KC G, Ranabhat S, Talwar O. Surface epithelial tumors of ovary - an analysis in a tertiary referral hospital. J Psychiat Neurosci. 2013;3(5):397-02.

12. Kanthikar S, Dravid N, Deore PN, Nikumbh D, Kishor S. Clinico-Histopathological Analysis of Neoplastic and Non-Neoplastic Lesions of the Ovary: A 3-Year Prospective Study in Dhule, North Maharashtra, India. J Clinic Diagnost Res. 2014;8.

13. Baru L, Patnaik R, Singh K. Clinico pathological study of ovarian neoplasms. Int $\mathrm{J}$ Reproduct Contracept Obstet Gynecol. 2017;6(8):3438-44.

14. Radhamani S, Akhila MV. Evaluation of Adnexal Masses - Correlation of Clinical, Sonological and Histopathological Findings in Adnexal Masses. Int J Scientif Stud. 2017;4(11):88-92

15. Kuladeepa AVK, Muddegowda PH, Linegowda JB, Doddikoppad MM, Basavaraja PK, Hiremath SS. Histomorphological study of 134 primary ovarian tumors. Adv Lab Int Med. 2011;1(4):69-82.

16. Goff BA, Mandel LS, Melancon CH, Muntz HG. Frequency of symptoms of ovarian cancer in women presenting to primary care clinics. J Am Med Assoc. 2004;291(22):2705-12. 
17. Ebell MH, Culp MB, Radke TJ. A Systematic Review of Symptoms for the Diagnosis of Ovarian Cancer. Am J Prev Med. 2016;50(3):384-94.
Cite this article as: Bagde ND, Bagde M, Agrawal S, Lone ZA, Hussain N. Do women with benign versus malignant ovarian masses demonstrate variable clinical presentation?. Int J Reprod Contracept Obstet Gynecol 2021;10:132-7. 